\title{
Designing an In-Silico Mimetic for Thrombopoietin Using Combinatorial Library
}

\author{
Vimal Kishor Singh $^{1}$, Ishita Goyal ${ }^{2}$, Abhishek Saini ${ }^{3}$, Neeraj Kumar ${ }^{4}$, Manisha Kalsan ${ }^{5}$, Ramesh Chandra ${ }^{6}$ \\ 1, 2, ${ }^{3}$ Stem Cell Research Laboratory, Department of Biotechnology, Delhi Technological University, Delhi, India \\ 4, 5, 6 Department of Chemistry, University of Delhi, Delhi, India
}

\begin{abstract}
Differentiation and proliferation of megakaryocytic progenitor cells into mature platelets is triggered and activated upon binding of Thrombopoietin Receptor (TPOR), a cytokine receptor protein, to thrombopoietin (TPO), a 95 KD glycoprotein hormone.TPO plays a very important role as it can easily direct Hematopoietic Progenitor Cells into the megakaryocytic lineage but even then very few mimetic have been reported, Agonists such as Romiplostim and Electrombopag are reported, recombinant TPO mimetic are also available but structural mimetic is only TMP, so the scope of further research is available. A promising approach for designing a mimetic can be targeting the binding site of the receptor such that the mimetic peptide has similar agonist activity as the ligand. Diverse libraries can be created using in-silico approaches and they are analyzed to bind receptor efficiently. In this study efforts are made for the development of TPO mimetic with therapeutic potential. TPO increases its number, prevent apoptosis, and thereby increases platelet production. Activation of TPO receptor leads to phosphorylation of the cytoplasmic domain as well as downstream activation of JAK2, STAT5, and other anti-apoptotic pathways. This increases the viability of stem cells and precursors of all lineages. The anti-apoptotic effect of TPO is probably important in patients with ITP: bone marrow megakaryocytes and megakaryocyte precursors are already increased but these cells are undergoing apoptosis mediated by anti-platelet IgG and T cells, thereby limiting platelet production. Administration of TPO decreases the apoptotic rate of the megakaryocyte precursors and thereby enhance the platelet production. Once produced, platelets are still affected by TPO. TPO's new Combinatorial library was designed by interaction sites of TPOR with TPO and previously reported TPO mimetic peptide (TMP), further screening of combinatorial library was done and an efficient mimetic was chosen based on scoring function commonly called Energy. Energy is calculated in terms of KJ/mol, based on the orientations generated by docking ligand with the receptor, the most efficient ligand has the most stable conformation with minimum energy value. In this study docking of TPO and TPOR has a minimum energy value of -518.20; TPOR and mimetic designed has a total score of -456.55 which is better than the known mimetic TMP, which has an energy score of -170.17 with TPOR. Computational approaches confirmed that the resulting peptide mimetic was stable and similar in nature to TPO. Further Ex-vivo study of designed mimetic can confirm its role in regenerative medicine, increasing the shelf life of platelet to improve cellular viability of platelet by preventing programmed cell death, i.e. apoptosis, which can be achieved by adding TPO during storage since TPO levels increase when platelet count is low, to stimulate additional production. TPO is absorbed by transfused platelets, which may decrease available TPO level or in the disease condition.
\end{abstract}

Keywords: Thrombopoietin, Thrombopoietin receptor, Mimetic, Library designing, Docking

\section{Introduction}

Platelets are the smallest cells in the blood. These cells are enucleated, discoid in shape and size ranges from 1-2 $\mu \mathrm{m}$. Platelets play an important role in maintaining homeostasis, healing wounds, and stop bleeding. Number of Platelet varies from $1.5-4 \times 10^{6}$ cells per microliter (per mcL) of blood.The average platelet count in women is considerably higher than men. Platelets are generated from megakaryocytes in the bone marrow and highly regulated by various growth factors [1]. The importance of the maintenance of both number of platelets and their functionality may be understood from the most common diseases associated with them, e.g.

- Thrombocythemia and reactive Thrombocytosis Abnormal increase in platelets; if blood has too many platelets, one may have a higher risk of blood clots.

- Thrombocytopenia - Decrease in platelets; if blood has a low number of platelets, one can be at risk of bleeding.

- Platelet dysfunction - The platelets are unable to stick together or attach to blood vessel walls hampering their normal function and this can cause excessive bleeding e.g. von Willebrand Disease.
In any of these conditions, hemostatic balance is disturbed and may lead to bleeding.

Disease condition where a patient is deficient in TPO, this approach can be miraculous.TPO plays an important role in hematopoiesis, any change in the hormone or to its receptor may trigger any congenital or acquired disease state of thrombocytopenia, thrombocytosis or aplastic anemia. Apart from the disease conditions, TPO can also help in improving the quality of platelet during storage condition. Platelets are generated from megakaryocytic cells in the bone marrow using a number of growth factors such as TPO, IL-2,3,6,11 surprisingly Hematopoietic Progenitor Cells can easily be directed into the megakaryocytic lineage by using only a single growth factor i.e. Thrombopoietin. TPO can improve cellular viability of platelet by preventing programmed cell death, i.e. apoptosis; and perhaps this could be helpful in achieving prolonged shelf life by adding TPO during storage since

a) TPO levels increase when the platelet count is low, to stimulate additional production.

b) TPO is absorbed by transfused platelets, which may decrease available TPO levels [2]. 


\section{International Journal of Science and Research (IJSR) \\ ISSN (Online): 2319-7064 \\ Index Copernicus Value (2013): 6.14 | Impact Factor (2015): 6.391}

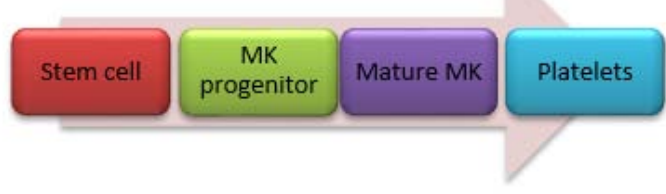

TPO

II-3

SCF

IL-11

IL-6

FLT 3

ARP

Figure 1: Regulation of megakaryocytopoiesis by various hematopoietic growth factors. Figure explains that amongst all the growth factors completing the process of megakaryocytopoiesis, TPO plays an important role at every stage. Through the process of platelet production, various growth factors play a role but TPO plays a very important role at all the stages beginning from Stem cell to MK progenitor cell to Mature MK to Platelets.

TPO is primarily synthesized in human liver parenchymal cells and kidney. It's a 353 amino acid protein which on the removal of the signal peptide of 21 amino acid forms a mature molecule. The mature molecule consists of two domains: receptor binding and carbohydrate rich region. Levels of TPO increase with a decline in platelet mass and remain elevated throughout thrombocytopenia. Structurefunction analysis of TPO has revealed that the thrombopoietin effect of the molecule is present in the $\mathrm{N}$ terminal i.e. first 153 amino acids only and it is all that is required for the activity but this truncated molecule has a reduced circulatory half-life, thus, it is presumed that the glycosylated second region provides stability and prolongs the circulatory half-life [3-5]

An experimental study in mice showed that mice deficient in TPO show a reduction of $90 \%$ in bone marrow megakaryocytes and circulating platelets quantity; and administration of TPO to normal mice increases platelet count almost 200\%, $500 \%$ increase in megakaryocytes and $1000 \%$ increase in bone marrow colony-forming unit megakaryocytes [6-7].

TPO is a $95 \mathrm{kDa}$ glycoprotein. It possesses 2 domain structures - Cytokine domain at the N-terminal,Carbohydrate domain at C-terminal. The cytokine domain comprises of first 153 amino acids up till Arg 153 followed by the carbohydrate domain which starts from Arg 154 till $332^{\text {nd }}$ amino acid. The carbohydrate domain shows no biological activity but still assists TPO to be soluble. It is also prototypically cleaved from the protein before it binds to its receptor.

TPO receptor (C-mpl) is a 635 amino acid protein. It has an extracellular domain of 485 amino acid starting from $26^{\text {th }}$ amino acid and ends at $491^{\text {st }}$ amino acid. TPO interacts with
c-MPL in the extracellular domain only. C-mpl has two extracellular subunits, namely subunit I from $26-277$ amino acids and subunit II from 253 - 491. Subunit I shows greater interaction with the ligand [8].

The specific interaction of TPO with c-MPL triggers a cascade of cellular signal, which involves,

- JAK2 and TYK2 pathways

- Mitogen-activated protein kinase pathway

- Phosphatidylinositol 3-kinase pathway

- Nuclear factor kappa B pathway (Kuter D., 1995)

Initially, a recombinant form of human TPO was developed as a first generation thrombopoietic agent, but their development was terminated because cross-reactivity was observed with endogenous TPO. Now second generation thrombopoiesis stimulating, these have distinguished pharmacological properties and show no homology to Thrombopoietin. Romiplostim and Eltrombopag are two agents which have completed phase III trials and they have been authorized for marketing for the use of disease purpose. There are very few peptides mimetic available for TPO so the efforts are being made for the same.

Numbers of previously reported TPO mimetic are very limited and thus, the scope of improving is more. New and improved approach for ligand discovery, based on combinatorial procedures of assembling a number of compounds to produce diverse molecules for binding molecular targets with higher specificity and efficiency can prove to be miraculous. Based on this same approach, we have designed a combinatorial library, consisted of oligopeptides. It was formed by oligopeptides derived from interaction sites TPOR with TPO and TMP and literature survey. TPO and TMP bind to TPOR in the extracellular domain and activate it in order to regulate thrombocytosis. Randomly varying various combinations of the peptides obtained is a possible approach to design a mimetic.

\section{Method and Methodology}

\subsection{Library Formation}

In this study, a peptide library was formed on the basis of interaction studies of TPOR with TPO and TMP (known mimetic) and literature survey. Interaction studies were used for library formation. Random changes of the amino acid at the different location were done for making various combinations of oligopeptide library.

\subsection{Receptor Protein Preparation}

TPO binds to TPOR on extracellular domain region (ECD). The 3D structure of TPOR was not available on RSCB protein data bank. So from NCBI protein sequence was retrieved and homology search was done. BLASTp using Protein data bank database was used for homology study. The result showed a maximum similarity of $24 \%$ with EPO, which was not enough for predicting structure, so using structure prediction tool phyre 2, based on ab-initio search and fold recognition, was used. Binding site (Extracellular 


\section{International Journal of Science and Research (IJSR) \\ ISSN (Online): 2319-7064 \\ Index Copernicus Value (2013): 6.14 | Impact Factor (2015): 6.391}

region) of TPOR protein was selected. Native TPOR protein was prepared for docking analysis using maestro. TPOR protein chains were identified for finding any duplication, duplicated chains were removed. Hydrogen was added to the protein molecule and then protein structure was selected for energy minimization and followed by optimization for docking analysis.

Table 1: Servers, databases, and software used in this study

\begin{tabular}{|c|c|c|}
\hline Tools & Function & Application \\
\hline BLAST & $\begin{array}{l}\text { For searching similar protein or nucleotide } \\
\text { sequences. }\end{array}$ & $\begin{array}{l}\begin{array}{l}\text { BLAST was used to determine homology of TPOR with the } \\
\text { database. }\end{array} \\
\text {. }\end{array}$ \\
\hline Cell predictor & $\begin{array}{l}\text { Determines the sub-cellular localization of } \\
\text { target protein. }\end{array}$ & $\begin{array}{l}\text { Shortlisted peptides were run through this tool for predicting the } \\
\text { subcellular localization. }\end{array}$ \\
\hline Hex 8.0.0 & Protein -protein docking server. & Peptide sequences were docked with the receptor. \\
\hline Pep fold & $\begin{array}{l}\text { Tool for prediction of the de novo 3D } \\
\text { structure of oligopeptides. }\end{array}$ & $\begin{array}{l}\text { Pep fold was used for predicting the 3D structure of the peptide } \\
\text { sequences. }\end{array}$ \\
\hline Phyre2 & $\begin{array}{l}\text { Tool for prediction of the de novo 3D } \\
\text { structure of proteins. }\end{array}$ & $\begin{array}{l}\begin{array}{c}\text { Phyre2 was used for predicting the 3D structure of protein } \\
\text { sequences. }\end{array} \\
\end{array}$ \\
\hline $\begin{array}{l}\text { Protein Data } \\
\text { Bank (PDB) }\end{array}$ & $\begin{array}{l}\text { PDB consists of a 3D structure of } \\
\text { biomolecules and their complexes. }\end{array}$ & $\begin{array}{c}\text { The 3D structure of protein were retrieved from PDB and used for } \\
\text { determining physicochemical properties. }\end{array}$ \\
\hline $\begin{array}{l}\text { Protein peptide } \\
\text { calculator }\end{array}$ & $\begin{array}{l}\text { Identifies various properties of a peptide } \\
\text { sequence. }\end{array}$ & $\begin{array}{c}\text { Shortlisted peptide sequences were run through the Protein peptide } \\
\text { calculator for determining physiochemical properties. }\end{array}$ \\
\hline ProtParam & $\begin{array}{l}\text { Identifies various properties of a peptide } \\
\text { sequence. }\end{array}$ & $\begin{array}{l}\text { Shortlisted peptide sequences were run through the ProtParam for } \\
\text { determining physiochemical properties. }\end{array}$ \\
\hline Pymol & $\begin{array}{l}\text { For a 3D view of proteins and analysis of } \\
\text { PDB structure. }\end{array}$ & $\begin{array}{l}\text { TPO-TPOR \& TMP-TPOR complexes and other 3D structure } \\
\text { viewed and analysed. }\end{array}$ \\
\hline
\end{tabular}

\subsection{TMP, Known mimetic preparation}

Known mimetic, TMP, was reported to mimic the role of TPO for activation and dimerization of TPOR. The 3D structure of the known mimetic was retrieved from Pepfold (mobyle server) in PDB format. For docking analysis, known mimetic was prepared by extracting water. PDB file was imported into Maestro workspace and prepared.

\subsection{Interaction analysis of TPOR with TMP and TPO}

PDB files of TPOR and TMP were imported into HEX 8.0.0 for docking analysis. Similar docking analysis was done for TPOR and TPO.

\subsection{Ligand preparation of peptide sequences}

Based on the interaction sites and literature survey a peptide library was generated. Random changes of the amino acid at different locations are done for making various combinations of oligopeptide library. In Peptide Library, first, the 3D structure was predicted by Pep fold peptide structure prediction server. Different peptides imported in the workspace of Pep fold and saving the project name and sequence and format allowed to run. Pep fold returned PDB file, which was processed further using Prep wizard.

\subsection{Interaction analysis of TPOR and combinatorial library of peptides-}

For peptide library (peptide sequences) binding energy is analysed by using the docking tool HEX 8.0.0. This required prepared receptor and ligand in PDB format. The receptor and ligand PDBs were imported into the workspace of HEX 8.0.0.HEX 8.0.0 gives binding energy in terms of $E_{\text {total }}$ score. Top 10 results were chosen for further analysis.

\subsection{Physiochemical and biological activity prediction-}

Selected mimetics were further analysed for physicochemical and Biological properties. Physiochemical properties \& Biological properties are determined using Peptide protein calculator, ProtParam, RAMPAGE and Cello server.

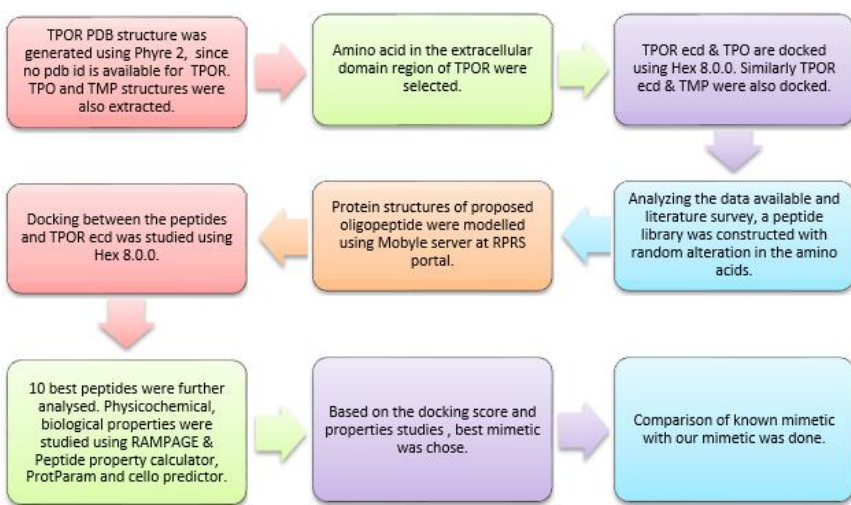

Table 2 Methodology used to design TPO mimetic. TPOTPOR complex was analysed to determine the interaction site was generated. A combinatorial library was generated by previously known mimetic and TPO and literature survey.

Prepared receptor protein and library compounds were

docked. Compounds were shortlisted on the basis of their docking results and further analysed for the physicochemical and biological properties.

\section{Results}

\subsection{Receptor Preparation}

TPOR BLAST result: BLASTp analysis, using protein data bank database, of TPOR sequence revealed that it has a maximum identity of $24 \%$ with EPOR, which is not enough to make a 3D structure based on homology alone. TPOR 3D structure Analysis- Literature study defined TPOR having two similar chains in pairs A, B and C, D binding to TPO. 


\section{International Journal of Science and Research (IJSR) \\ ISSN (Online): 2319-7064 \\ Index Copernicus Value (2013): 6.14 | Impact Factor (2015): 6.391}

Receptor-ligand binding critically depends on the orientation of interaction. Both pairs of chains of TPOR have similar amino acid sequences so for docking analysis duplicated chain C \& D is removed from the receptor protein. Protein is prepared using Prep wizard by importing receptor file and minimizing and optimizing the receptor protein.
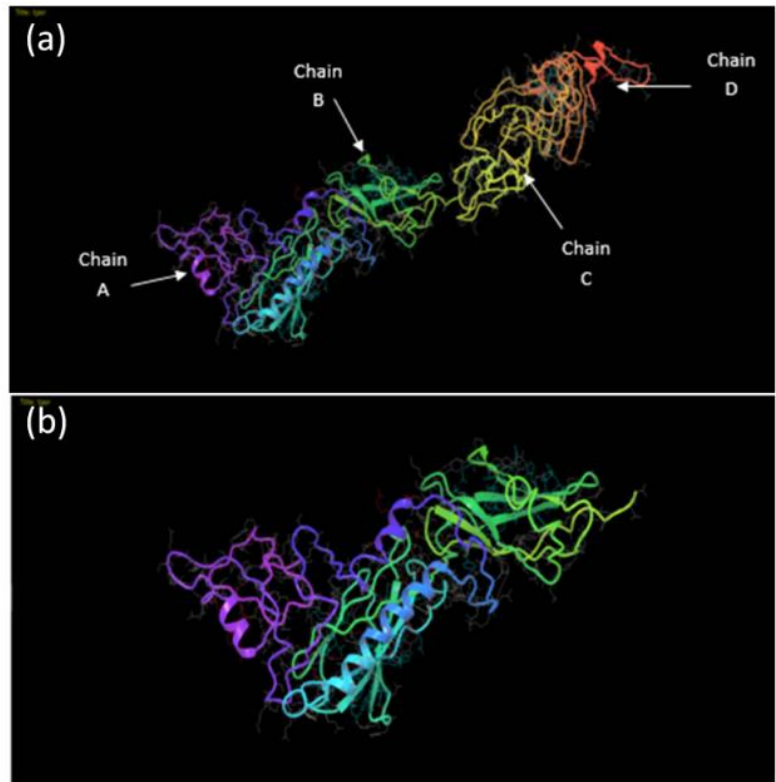

Figure 2 a) The 3D structure of TPOR indicating various chains in the structure. Chain A \& chain B are identical to chain $C \&$ chain $D$ so only one set of chains are considered for further study. b) 3D structure of TPOR, representing chains $A \& B$. (after removing duplicate chains $C \& D$ and water molecules)
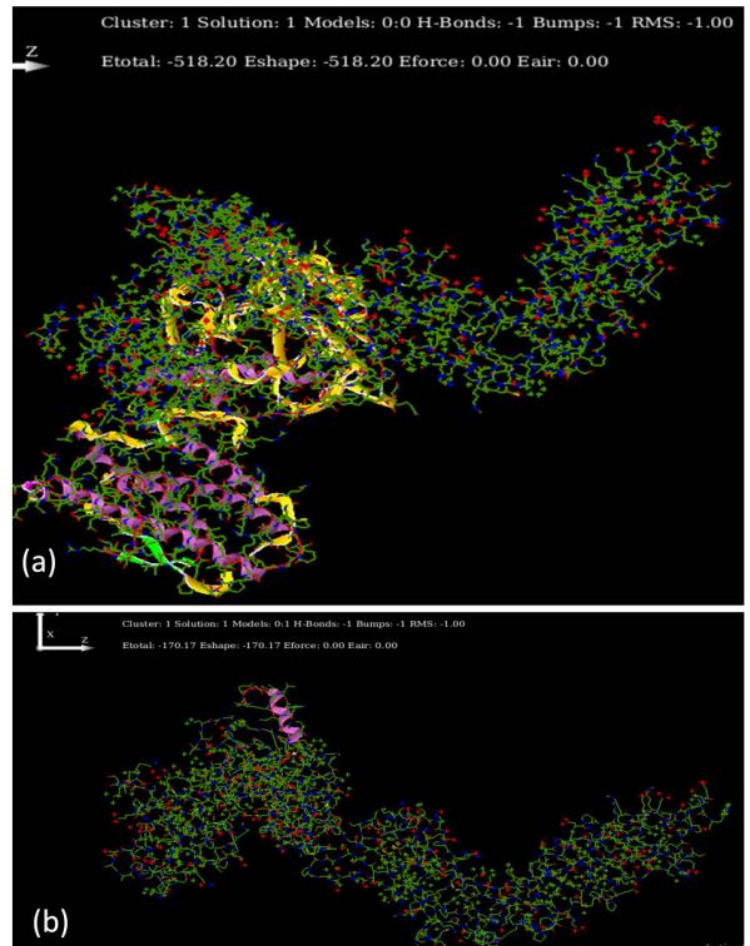

Figure 3 a) Interacting TPO-TPOR and showing binding sites. Docking study gave an $E_{\text {total }}$ of -518.20.Identified residues which are interacting were - V44, D45, F46, S47, L48, E50, A126, L129, Q132, H133, R140, F141, and L144.

b) docking analysis of TPOR-TMP. $E_{\text {total }}$ of -170.17 was observed in when TPOR and TMP were docked using HEX 8.0.0.

\subsection{Interaction analysis of TPOR with TPO \& TMP}

Prepared receptor protein TPOR was docked with TPO and known mimetic TMP using HEX 8.0.0 server. PDB files of receptor and ligand imported and interaction domain and number out coming result 10 were selected. Best resulting PDB of ligand and receptor analysed to determining binding sites. Random combination of these amino acids made and peptide sequences predicted.

\subsection{Library formation- Peptide mimetic predication}

Peptide sequences were predicted on the basis of binding site of TPO and TMP with TPOR. First protein is prepared and docking is allowed.

\subsection{Library Generation}

Pepfold a de-novo peptide structure prediction tool was used to predict 3D structures of peptides Peptide sequences were pasted on the workspace and allowed to run which gives $3 \mathrm{D}$ structure in PDB format. PDB files imported to Maestro and Prepwizard used to prepare structures.

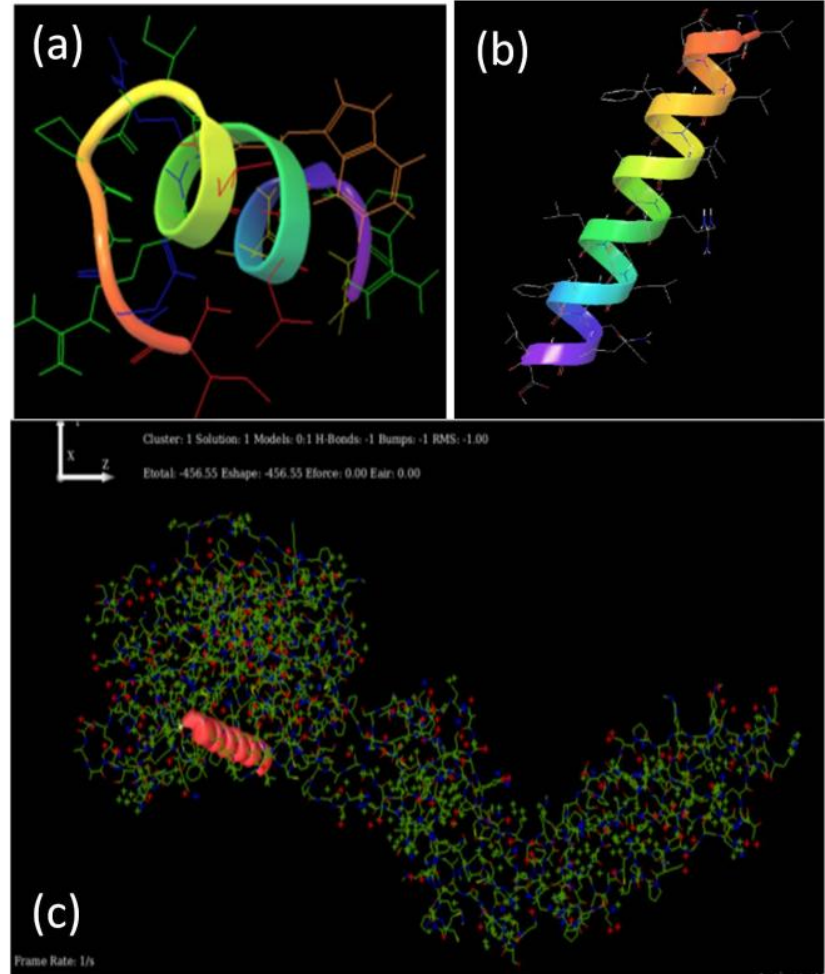

Figure 4: a) 3D structure for TMP retrieved from Pep fold.

b) Peptide 1 retrieved from pep fold and processed in maestro, c) Peptide 1 interacting to its target TPOR

3.5 Interaction analysis of TPOR and combinatorial library of peptides-

A combinatorial library of peptides interaction with TPOR was analysed using HEX 8.0.0 software. Initially, receptor and ligand were prepared for removing water and unwanted ligands then PDBs of receptor and ligand peptides were

\section{Volume 5 Issue 4, April 2016}




\section{International Journal of Science and Research (IJSR) \\ ISSN (Online): 2319-7064}

Index Copernicus Value (2013): 6.14 | Impact Factor (2015): 6.391

uploaded to the software. Parameters of interaction analysis calculation device number of results and domain of interaction are selected and then the programme was run. Hex returned the $E_{\text {total }}$ score and best PDBs for the interaction of receptor and ligand were obtained. (Table: 3)

Table 3: $\mathrm{E}_{\text {total }}$ score of TPOR and peptide library using HEX 8.0.0. Known and Unknown peptide mimetic with their scores. Peptide-1 has better Energy total score than other peptides.

\begin{tabular}{|c|c|c|}
\hline S.No & Oligopeptides & $E_{\text {total }}$ \\
\hline \multicolumn{3}{|c|}{ Known mimetic } \\
\hline 0 & IEGPTLRQWLAARA(TMP) & -170.17 \\
\hline \multicolumn{3}{|c|}{ Unknown mimetic } \\
\hline 1 & VLDLLFTVLAARLLVLLFFQL & -456.55 \\
\hline 2 & LLELLFIVLAARLLVLLFFQLL & -333.85 \\
\hline 3 & LLSLIVLAARLLVLLFFQLLLF & -299 \\
\hline 4 & LLSLLFIVLAADELVLLFFQLL & -333.66 \\
\hline 5 & SPAPPACQVHPLPTPVLLPAVDFSLG & -356.03 \\
\hline 6 & LLSLLFIVLAARLLVLLFFQLL & -340.91 \\
\hline 7 & LLSLLFIVLAAHLLVLLFFQLH & -333.51 \\
\hline 8 & SPAPPACQVHPLPTPVLLPAVDF & -300.07 \\
\hline 9 & LLSLLFIVLAAHLLVLLFFQLH & -315.22 \\
\hline 10 & LLSLLFIVLEAHLLVLLDFQLH & -330.2 \\
\hline 11 & SPACQVHLTDFGEWKQMIRQ & -300.44 \\
\hline 12 & EDKRKHTQRRNH & -252.85 \\
\hline 13 & THRRKKRDGWEQNH & -252.85 \\
\hline 14 & WQDRKPELLRKLRNH & -194.78 \\
\hline 15 & SPAPPACQVHPLPTPVLLPA & -256.49 \\
\hline 16 & SPAPPACQVHPLPTPVL & -138.59 \\
\hline 17 & CRNEAESHYCYYNNASHL & -209.83 \\
\hline 18 & NQDRKPELLRKLRNH & -225.85 \\
\hline 19 & LLSLLFRVLAADELVLLKFQLL & -276.24 \\
\hline 20 & LLSLLFIVADRLLVLLFFQLL & -233.35 \\
\hline 21 & ILVGTLIVLIPVLIVLVFLYWQ & -266.99 \\
\hline
\end{tabular}

\subsection{Physicochemical properties of peptide}

Peptide mimetic with better binding energy value was further evaluated for physicochemical properties using Protein peptide calculator and Protparam. The results obtained from the software were the physiochemical parameters such as molecular weight, isoelectric $\mathrm{pH}$, nature and charge of the peptides, estimated half-life, and instability index.

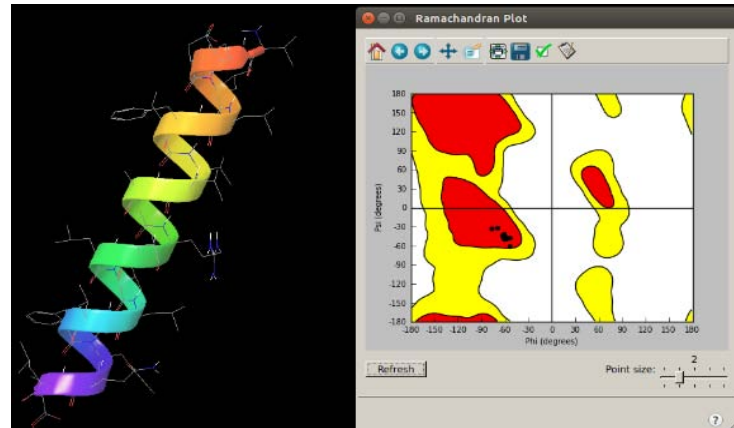

\section{Evaluation of residues}

Number of residues in favoured region ( $98.0 \%$ expected): 20 (100.0\%) Number of residues in allowed region ( $\sim 2.0 \%$ expected): $0(0.0 \%)$ Number of residues in outlier region : $\theta(0.0 \%)$

Figure 5: Ramachandran plot generated for Peptide 1 along with details of residues by RAMPAGE.
Table 4 Peptide 1 parameters identification using protein peptide calculator and ProtParam. Various parameters studied were Molecular weight, Isoelectric $\mathrm{pH}$ - The value of $\underline{\mathrm{pH}}$ at which a particular molecule carries no net electrical charge, Charge, Nature, Estimated half-life- It is basically a prediction of time for half of the amount of protein in a cell to disappear after its synthesis. ProtParam place reliance on the "N-end rule", in which the half-life of a protein relies on its $N$-terminal residue; the prediction is given for 3 model organisms namely, human, yeast and E.coli. The N-terminal residue of a protein also plays an important role in determining its stability in vivo, Instability index - It determines whether it will be stable in a test tube. If the index is greater than 40 , then it is probably unstable in the test tube.

\begin{tabular}{|c|c|c|}
\hline Parameters & $\begin{array}{l}\text { Values for } \\
\text { Peptide-1 }\end{array}$ & $\begin{array}{l}\text { Values for } \\
\text { TMP }\end{array}$ \\
\hline $\begin{array}{l}\text { Molecular } \\
\text { weight }\end{array}$ & 2543.24 & 1581.8 \\
\hline Isoelectric $\mathrm{pH}$ & 6.23 & 10.45 \\
\hline Charge & 0 & 1 \\
\hline Nature & Neutral & basic \\
\hline $\begin{array}{l}\text { Estimated half- } \\
\text { life }\end{array}$ & $\begin{array}{l}100 \text { hours } \\
\text { (mammalian } \\
\text { reticulocytes, } \\
\text { in vitro). } \\
>20 \text { hours } \\
\text { (yeast, in } \\
\text { vivo). } \\
>10 \text { hours } \\
\text { (Escherichia } \\
\text { coli, in vivo). }\end{array}$ & $\begin{array}{l}20 \text { hours } \\
\text { (mammalian } \\
\text { reticulocytes, } \\
\text { in vitro). } \\
30 \text { min (yeast, } \\
\text { in vivo). } \\
>10 \text { hours } \\
\text { (Escherichia } \\
\text { coli, in vivo). }\end{array}$ \\
\hline $\begin{array}{l}\text { Instability } \\
\text { index }\end{array}$ & $\begin{array}{l}5.69 \text { (This } \\
\text { classifies the } \\
\text { protein as } \\
\text { stable) }\end{array}$ & $\begin{array}{l}77.00 \quad \text { This } \\
\text { classifies the } \\
\text { protein as } \\
\text { unstable) }\end{array}$ \\
\hline
\end{tabular}

\section{No. of residues}

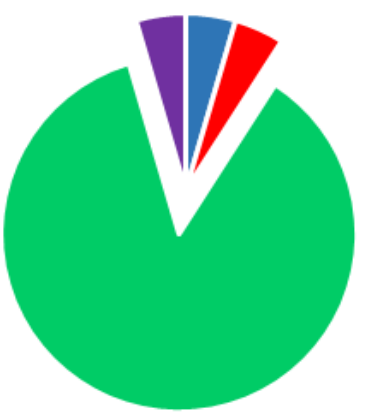

- acidic residue

- basic residues

- hydrophobic uncharged residues

a other residues

Figure 6: Hydrophilicity analysis of peptide 1 obtained from protein peptide calculator. We can conclude that the number of uncharged hydrophobic residues are maximum in number

i.e. 19 and the other three namely acidic residue, basic residue, other residues are 1 each. With the colour code, the sequence will be written as VLDLLFIVLAARLLVLLFFQLL. 


\section{International Journal of Science and Research (IJSR) \\ ISSN (Online): 2319-7064}

Index Copernicus Value (2013): 6.14 | Impact Factor (2015): 6.391

\subsection{Biological properties of peptide}

Cello predictor server is used for the Subcellular localization of the peptide-1. Subcellular localization can be correlated to the biological function of a protein It determines the localization of peptides after secretory pathway.

Table 5 Cello predictor results of Peptide- 1 for determining the localization in the cell.

\begin{tabular}{|l|l|l|l|}
\hline Extracellular & 1.266 & Peroxisomal & 0.034 \\
\hline Nuclear & 1.134 & ER & 0.028 \\
\hline Mitochondrial & 0.891 & Golgi & 0.019 \\
\hline Chloroplast & 0.759 & Cytoskeletal & 0.018 \\
\hline Cytoplasmic & 0.496 & Vacuole & 0.018 \\
\hline Plasma Membrane & 0.320 & Lysosomal & 0.017 \\
\hline
\end{tabular}

\section{Discussion}

Designing an in-silico mimetic for Thrombopoietin to improve the cellular viability of platelet by preventing programmed cell death, i.e. apoptosis or to treat plateletassociated diseases like aplastic anemia, etc., via a combinatorial library of peptide sequence derived from binding sites of TPOR with TPO and known mimetic and literature survey is created. The library was tested for interaction analysis with TPOR extracellular domain region for binding and regulation of thrombopoiesis. For the interaction study, first in the receptor, TPOR, extracellular domain region was prepared by structure prediction method via phyre 2 and then by removing water structure was prepared. A similar procedure was followed for TPO since PDB structures for both the proteins is not available. The TPO-TPOR active site is analyzed using PDB structure of the complex obtained from docking results by HEX 8.0.0 in maestro server. TPOR found to interact with two regions in TPO forming the receptor dimer. Hydrophobic amino acids, namely, His133, Lys14, Lys138, and Phe141 are present in the receptor binding site. Peptide mimetic 1 has an $\mathrm{E}_{\text {total }}$ value of -456.55 which is better than the $E_{\text {total }}$ value of known mimetic TMP, -170.17. Lead Peptide mimetic was further analyzed for physicochemical properties and stability. Peptide mimetic showed higher hydrophobicity which is similar to natural TPO variant and is necessary to the membranes. Lead peptide hydrophilic and hydrophobic nature may have an important role in binding to TPOR as we had seen polar and non-polar both interactions involved in binding of TPO-TPOR complex. Cello predictor results showed that peptide localization by secretary pathway is to the cytoplasm where it can bind to its receptor and activate the signaling further for platelet formation. In future, further Ex-vivo study of designing mimetic with TPOR can confirm its role in increasing the shelf life of the platelet by acting as an anti-apoptotic agent or in the diseased condition and more importantly can be used for ex vivo platelet generation and in many other applications in the field of regenerative medicine.

\section{Conclusion}

Peptides are conveniently modified using computational tools for in-silico study. In silico study helps in improving peptide in terms of stability, to further enhance the therapeutic potential. This would reduce the time and expenses of in vivo and in-vitro experiments. In this study, using computational tools an attempt was made to design novel TPO mimetic which would activate TPOR cytokine protein and consequent signaling. TPO is an essential factor for platelet, MK progenitor cells viability, and proliferation. We identified that peptide 1 from the library generated has a high binding affinity towards TPOR. On studying physiochemical and biological properties the predicted mimetic was acceptable with high stability. In future, the designed mimetic would be a promising candidate for treating aplastic anemia, thrombocytopenia, Thrombocythemia, and other platelet dysfunctional diseases. Mimetic can play an important role in increasing the shelf life of platelet by acting as an antiapoptotic agent.

\section{References}

[1] Machlus KR, Italiano JE Jr. The incredible journey: From megakaryocyte development to platelet formation. J Cell Biol. 2013 Jun 10;201(6):785-96. doi: 10.1083/jcb.201304054

[2] Christian H, Rüster B, Seifried E, Henschler R. . Platelet precursor cells can be generated from cultured human CD34+ progenitor cells but display recirculation into hematopoietic tissue upon transfusion in mice. Transfus. Med. Hemother. 2010. 37, 185-190 10.1159/000316975

[3] Kuter DJ, Rosenberg RD. The reciprocal relationship of thrombopoietin (c-Mpl ligand) to changes in the platelet mass during busulfan-induced thrombocytopenia in the rabbit. Blood. 1995 May 15;85(10):2720-30.

[4] Kuter DJ. Thrombopoietin and thrombopoietin mimetics in the treatment of thrombocytopenia. Annual Review of Medicine, 2009, 60, 193-206. http://doi.org/10.1146/annurev.med.60.042307.181154

[5] Kuter DJ. Review article New thrombopoietic growth factors 2015, 109(11), 4607-4617. http://doi.org/10.1182/blood-2006-10-019315.

[6] Chen WM, Yu B, Zhang Q, \& Xu P. Identification of the residues in the extracellular domain of thrombopoietin receptor involved in the binding of thrombopoietin and a nuclear distribution protein (human NUDC). Journal of Biological Chemistry, 2010, 285(34), 26697-26709. http://doi.org/10.1074/jbc.M110.120956

[7] Harker LA, Hunt P, Marzec UM, Kelly AB, Tomer A, Hanson SR, Stead RB. Regulation of platelet production and function by megakaryocyte growth and development factor in nonhuman primates. Blood. 1996 Mar 1;87(5):1833-44.

[8] Hsieh DPH, Huxtable S, Ng K F, Chen HM, Tsang PWK, Wang J, \& Xu P. Determination of interactions between human thrombopoietin and its receptor MPL by yeast two-hybrid system and affinity biosensor. International Journal of Biochemistry and Cell Biology, 2000, 32(5), 481-488. http://doi.org/10.1016/S13572725 (99)00132-6. 


\section{Author Profile}

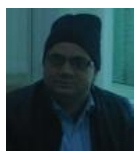

Dr. Vimal Kishor Singh received the M.Sc. in BioMedical Sciences from University of Delhi. PhD from Institute of Nuclear Medicine and Allied Sciences (DRDO)/University of Delhi Founder and O/I of Stem Cell Research Laboratory, Dept. of Biotechnology, Delhi Technological University

Ishita Goyal received the M.Tech degree in Bioinformatics from Delhi Technological University in 2015. Her area of interest lies in computational biology, protein-protein docking.

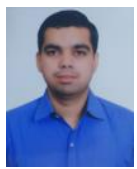

Abhishek Saini received the B.Sc. Microbiology (H) degree from Delhi University and M.Sc. in Biotechnology from TERI University. At present pursuing Ph.D. from Delhi Technological University.

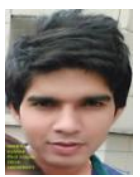

Neeraj Kumar received the B.Sc. degree in Chemistry from Delhi University and the M.Sc. degree in Biochemistry from Jamia Millia Islamia University and M.Tech degree in Bioinformatics from Delhi Technological University. Presently, pursuing his Ph.D. from Delhi University.

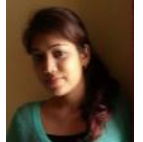

Manisha Kalsan received a B. Tech degree in Biotechnology from D. C. R. University of Science and Technology, Murthal and an M. Tech degree in Bioinformatics from Delhi Technological University and is presently pursuing her PhD from University of Delhi.

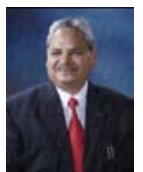

Prof Ramesh Chandra is founder Director of ACBR, University of Delhi. Former Vice-Chancellor, Bundelkhand University Professor, Department of Chemistry, University of Delhi. 